\title{
Lung cancer screening: No more excuses
}

\author{
Betty C. Tong, MD, MHS
}

\footnotetext{
From the Division of Thoracic and Cardiovascular Surgery, Department of Surgery, Duke University Medical Center, Durham, NC.

B.C.T. is a member of the National Comprehensive Cancer Network (NCCN) Lung Cancer Screening Guidelines Panel.

Disclosures: Author has nothing to disclose with regard to commercial support.

Received for publication Aug 25, 2017; accepted for publication Aug 26, 2017; available ahead of print Sept 21, 2017.

Address for reprints: Betty C. Tong, MD, MHS, DUMC 3531, Durham, NC 27710 (E-mail: betty.tong@duke. edu).

J Thorac Cardiovasc Surg 2018;155:369-70

0022-5223/\$36.00

Copyright (C) 2017 by The American Association for Thoracic Surgery

http://dx.doi.org/10.1016/j.jtcvs.2017.08.090
}

It has been 6 years since the National Lung Screening Trial demonstrated a $20 \%$ decreased mortality when using low-dose computed tomography (LDCT) to screen for lung cancer in individuals at high risk. ${ }^{1}$ Even though lung cancer screening (LCS) is endorsed by the US Preventative Services Task Force and The American Association for Thoracic Surgery (among others) and is reimbursed by the Centers for Medicare and Medicaid Services, uptake has been slow. Between 2010 and 2015, only 3.3\% to 3.9\% of eligible smokers in the United States actually underwent LDCT screening. ${ }^{2}$ Several barriers to screening have been reported, including lack of endorsement by national societies, such as the American Association of Family Practitioners, ${ }^{3}$ lack of awareness of guidelines, and lack of knowledge by providers regarding where to refer screening-eligible patients. ${ }^{4-6}$ Moreover, hospital organizations and administrators are discouraged from providing LCS because of perceived cost considerations. The 2017 Hospital Outpatient Payment System proposed rule decreased reimbursement rates for LDCT shared decision making (G0296) and LDCT scans (G0297) by $64 \%$ and $44 \%$, respectively.

In this issue of the Journal, Gilbert and colleagues ${ }^{7}$ describe the economic impact of a nurse practitioner-led lung cancer screening program. In their analysis, they accounted for direct evaluation and management billing by the nurse practitioner, as well as for direct revenue generated by follow-up studies and procedures that occurred as a result of the evaluation and management services. Relative to the approximate "cost" of $\$ 420,000$ in the nurse practitioner's salary and benefits for 3 years, the overall revenue associated with the programs was $\$ 733,336$. On a per patient basis, this was approximately $\$ 1056$. Although this revenue is lower than the downstream revenue of $\$ 1763 /$ patient reported by others, ${ }^{8}$ Gilbert and colleagues $^{7}$ did not account for potential indirect sources, such as revenue from short-term follow-up studies recommended for patients with Lung-RADS (Lung Imaging Reporting and Data System) 3- and 4A findings.

\section{References}

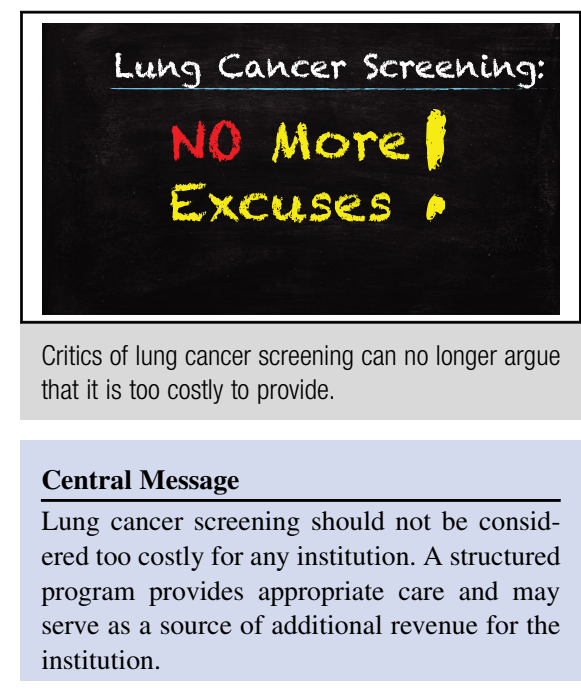

See Article page 416.

Additional-but as yet unmeasured-potential revenue also exists for patients requiring adjuvant therapies for lung cancer treatment.

It is also notable that Gilbert and colleagues ${ }^{7}$ performed LCS in the way that it is intended and mandated by the Centers for Medicare and Medicaid Services, with documented shared decision making and tobacco cessation counseling. It is currently unclear whether providers ordering LDCT studies outside the context of a screening program are able to achieve this. My own group's research demonstrated that a minority of providers outside the LCS program performed appropriate shared decision making and tobacco cessation counseling. ${ }^{9}$

The study of Gilbert and colleagues ${ }^{7}$ should help to refute the perception that LDCT screening is costly. One could, in fact, argue that it is more costly not to screen patients and continue the status quo, in which more than $50 \%$ of patients with lung cancer have their disease diagnosed at stage IIIB and IV. Appropriate counseling and LDCT screening, in a model such as that described by Gilbert and colleagues, can be lifesaving. LDCT screening should not be considered too costly for any facility. We must recognize that LDCT LCS is at the least cost neutral, and it potentially is profitable for the institution. There are no more excuses not to provide LCS services. We owe it to our patients to promote and support these efforts.

1. Aberle DR, Adams AM, Berg CD, Black WC, Clapp JD, Fagerstrom RM, et al; National Lung Screening Trial Research Team. Reduced lung-cancer mortality 
with low-dose computed tomographic screening. N Engl J Med. 2011;365: 395-409.

2. Jemal A, Fedewa SA. Lung cancer screening with low-dose computed tomography in the United States - 2010 to 2015. JAMA Oncol. February 2, 2017 [Epub ahead of print].

3. American Academy of Family Physicians. Clinical preventive service recommendation: lung cancer. Available at: http://www.aafp.org/patient-care/ clinical-recommendations/all/lung-cancer.html. Accessed August 20, 2017.

4. Ersek JL, Eberth JM, McDonnell KK, Strayer SM, Sercy E, Cartmell KB, et al. Knowledge of, attitudes toward, and use of low-dose computed tomography for lung cancer screening among family physicians. Cancer. 2016;122:2324-31.

5. Lewis JA, Petty WJ, Tooze JA, Miller DP, Chiles C, Miller AA, et al. Low-dose CT lung cancer screening practices and attitudes among primary care providers at an academic medical center. Cancer Epidemiol Biomarkers Prev. 2015;24:664-70.
6. Volk RJ, Foxhall LE. Readiness of primary care clinicians to implement lung cancer screening programs. Prev Med Rep. 2015;2:717-9.

7. Gilbert CR, Robb E, Fathi JT, Louie BE, Wilshire CL, Modin H, et al. The economic impact of a nurse practitioner-directed lung cancer screening, incidental pulmonary nodule, and tobacco cessation clinic. J Thorac Cardiovasc Surg. 2018; $155: 416-24$

8. Lanni TB Jr, Stevens C, Farah M, Boyer A, Davis J, Welsh R, et al. Early results from the implementation of a lung cancer screening program: the Beaumont Health System experience. Am J Clin Oncol. December 8, 2015 [Epub ahead of print].

9. Christensen J, Garst J, Wahidi M, Hogan C, Crittenden H, Bruce S, et al. P1.03-048 A structured lung cancer screening program facilitates patient and provider compliance. J Thorac Oncol. 2017;12(1 Suppl):S294. 